\title{
REGULATIONS RELATING TO THE \\ EXAMINATIONS OF THE ROYAL COLLEGE OF PHYSICIANS \\ AND SURGEONS OF CANADA
}

The Training Requirements in Anaesthesia

During the course of training the candidate must acquire a knowledge of the basic sciences necessary to the understanding and practice of Anaesthesia. This may be done concurrently with the resident training by attendance at special courses in basic science, or by spending specific periods of full-time training in basic science. The candidate must supply documentary evidence of having fulfilled this requirement by either of these methods.

\section{Training Requirements}

Examination in Anaesthesia Fellowship and Certification

1. An approved general interneship of at least one year.

2. Four years of graduate training in addition to the general interneship. This period must include:

(a) One year of approved resident training in Internal Medicine, or six months of approved resident training in Internal Medicine, and six months of approved resident training in General Surgery, or Obstetrics and Gynaecology.

(b) Two years of approved resident training in Anaesthesia.

(c) One year of training which may include:

i) One further year of approved resident training in Anaesthesia.

ii) One year as a clinical research fellow in a department approved by the College.

iii) One year in the full-time study of basic science in a department approved by the College.

iv) If no time was spent on surgery under $2(a)$, six months of approved resident training in surgery and six months of approved full-time study of basic science.

v) One year in approved course of study and training at a hospital or university centre in Canada or abroad.

\section{Equivalent of General Interneship}

The Credentials Committee will decide whether applicants from countries where a general interneship is not customary (or not obtainable), have had other or similar training which may be accepted as the equivalent of one year of general interneship.

\section{Preceptorship Training}

Preceptorship training is not accepted in fulfilment of any part of the training requirements for the examinations.

Training Abroad

A candidate who proposes to go abroad for training should seek approval of the proposed training by the Credentials Committee before departure from Canada. Applications for acceptance of such training already taken will be given 
individual consideration but there can be no assurance that the training will be accepted.

\section{Licensing Requirements}

A licence to practise in Canada or domicile in Canada is not required for admission to the examinations.

Unusual or Interrupted Training

Training which has not been taken continuously after graduation and which may have been taken in part while in private practice or other medical work, including research in medical science, will be assessed on its merits.

\section{The Examinations in Anaesthesta}

\section{Fellowship Examination in Medicine Modified for Anaesthesia}

The examination will consist of a written examination and of an oral and clinical examination.

(a) The Written Examination will consist of three papers:

Paper No. 1. The Principles and Practice of Medicine with emphasis on the application of Medicine to Anaesthesia.

Paper No. 2. The Principles and Practice of Anaesthesia.

Paper No. 3. Clinically Applied Basic Sciences including Anatomy. Physiology, Pharmacology, Pathology, Physics and Biochemistry, with emphasis on the application of these sciences to Anaesthesia.

(b) The Oral and Clinical Examination will consist of two parts:

(1) An oral and clinical examination conducted by a Board of Examiners consisting of two or more anaesthetists and at least one physician.

(2) An oral examination in the approved basic sciences pertaining to Anaesthesia conducted by a Board of Examiners consisting of two or more anaesthetists, at least one physician and a physiologist and/or pharmacologist. Emphasis will be placed on the principles of physiology and pharmacology and their clinical application to Anaesthesia. The candidate will be expected to demonstrate a broad knowledge of the other required basic sciences; anatomy, physics, biochemistry and pathology.

\section{Certification Examination in Anaesthesia}

The examination will consist of a written examination and an oral and clinical examination. The Examining Board will consist of two or more anaesthetists.

(a) The Written Examination will consist of two papers:

Paper No. 1. The Principles and Practice of Anaesthesia.

Paper No. 2. The Application of the Basic Sciences necessary to the proper understanding of Anaesthesia.

(b) The Oral and Clinical Examination

The candidate will be asked questions dealing with the principles of medicine, pathology and the related basic sciences necessary to the proper understanding of anaesthesia, as well as with the principles and practice of anaesthesia, and in addition will be examined on assigned patients.

For information write to: The Secretary, The Royal College of Physicians and Surgeons of Canada, 74 Stanley Ave., Ottawa 2, Ontario. 